\title{
How Does Price of Bitcoin Volatility Change?
}

\author{
Yutaka Kurihara $^{1} \&$ Akio Fukushima ${ }^{2}$ \\ ${ }^{1}$ Department of Economics, Aichi University, Nagoya, Japan \\ ${ }^{2}$ Institute of Economic Studies, Seijo University, Tokyo, Japan \\ Correspondence: Yutaka Kurihara, Aichi University, Nagoya, Japan.
}

Received: January 21, $2018 \quad$ Accepted: February 17, $2018 \quad$ Online Published: February 28, 2018

doi:10.20849/iref.v2i1.317

URL: https://doi.org/10.20849/iref.v2i1.317

This work was supported by JSPS KAKENHI Grant Number $15 H 03366$.

\begin{abstract}
The trading volume of Bitcoin has increased immensely since its conception. Bitcoin is a cryptocurrency, it is not a legal currency but rather a private monetary system that manages by itself and does not depend on governments or central banks. It is an autonomous currency system that is not liable to any governing body. Some fear that the increase of Bitcoin usage, as it is quite different from traditional currencies and is free from control or regulations by monetary authorities. Although its popularity has grown worldwide, fluctuations of the prices are sometimes erratic. Hence, such large and sudden movements would dampen the sound development of Bitcoin. This paper examines how the volatile price of Bitcoin changes empirically. The empirical results show that there is a difference between short-term volatility and long-term volatility. Traders should see not only the short-term movements in volatile Bitcoin pricing but also long-term developments.
\end{abstract}

Keywords: Bitcoin, price volatility of Bitcoin

\section{Introduction}

Bitcoin, created in 2008, is the most innovative digital currency (Zhu, Dickinson, \& Li, 2017). Bitcoin is a cryptocurrency, and it was first outlined by Nakamoto in 2009. Bitcoin is not a legal currency but a private monetary system that manages itself and does not depend on central banks or governments (see, e.g., Dowd \& Hutchinson, 2015). The trading volume has been expanding rapidly, so some people fear the trend as it is free from control and regulations by monetary authorities. Bitcoin can be inflated or deflated at will as the supply of Bitcoin is limited to a certain volume, which cannot be changed. The use of Bitcoin allows users to send or receive large amounts of money to anyone with cheaper costs than other financial instruments.

Beer and Weber (2014) showed that the network and financial services related to Bitcoin are not regulated, so users should take measures to protect their Bitcoin holdings by themselves. On the other hand, as indicated by William (2016), Bitcoin must reduce regulatory issues for use as they contain legal or regulatory problems. McCallum (2015) mentioned, "There exists a rather prominent possibility that the U.S. government will take legal steps to constrain or banish the Bitcoin system". Maftei (2014) indicated that Bitcoin transactions have expanded rapidly, which may catalyze regulation steps or legal approval of governments. However, Bitcoin could provide new hopes for greater freedom in terms of volume, payment methods, anonymity, etc. Kurihara and Fukushima (2017) proposed that the share will be large and evolve significantly over time for the various kinds of information. Brandvold, Molnar, Vagstad, Andreas and Ole (2015) determined that sound trading and boosting economies via Bitcoin is expected.

The characteristics meet users' strong demands, and Bitcoin has been accepted with demand by users all over the world. No other similar financial instruments exist to date, and it has attracted much attention since it's inception. This kind of cryptocurrency has grown and will grow due to emergence of newer technologies and applications (Abboushi, 2017). Most people believe that Bitcoin contains risk for transactions and investments. However, Bitcoin has been used for many types of transactions and investments and has been accepted by many users, which indicates a rapid increase in the trading volume of Bitcoin. Some serious incidents have occurred in reality, but the value of Bitcoin overcame and will overcome such serious conditions from now on, too. Now, the 
forward market is prevailing. There is some possibility that Bitcoin will be linked with new financial instruments such as financial derivatives.

Bitcoin has received much attention recently from academic fields and from the real world as there are a lot of usage objects. Brère, Oosterinck, and Szafarz (2015) showed that Bitcoin gives diversification of financial investments. Dyhrberg (2016) indicated that Bitcoin provides a hedge instrument for performing financial transactions. On the other hand, as noted by Seigh (2015) and Baeck and Elbeck (2015), Bitcoin has been used for speculation. Yermack (2013) indicated that Bitcoin appears to be used more as a speculative financial instrument than as a typical currency transaction. Also, Cheah and Fry (2015) found that the fundamental return of Bitcoin is almost zero, and Bitcoin shows speculative bubble elements. Bitcoin seems to have a place in financial markets and in portfolio management, however, there exist some kinds of speculative elements which may cause serious financial crisis.

The price stability of Bitcoin is at least as important as the price of Bitcoin because it relates to economic activity. If Bitcoin prices fluctuate or Bitcoin loses its value extremely, participants avoid its use, which can damage efficient allocation of resources in the economy. Bitcoin is still fairly young, so the data accumulation that examines the prices of Bitcoin is not sufficient. Experiences of using Bitcoin are rare. Examination of the prices and movements of Bitcoin is strongly necessary; however, few studies have tackled this problem. This paper examines the return volatility of Bitcoin. Dwyer (2014) indicated that the price volatility of Bitcoin is higher than the volatility of gold prices or some kinds of tangible currencies. Gronwald (2014) showed that Bitcoin prices are characterized by large price fluctuations such as those found in newly emerging markets. Cheung, Roca, and $\mathrm{Su}$ (2015) found that Bitcoin price bubbles are different than normal price movements. However, there are also few studies that examine the price volatility of Bitcoin.

There is also a need to explore other aspects of Bitcoin trading. For example, Yamori and Kurihara (2004) analyzed foreign exchange rate anomalies in a week. This study is not directly related with Bitcoin, but there are some possibilities that such kinds of anomalies should be taken into account. Kurihara and Fukushima (2017) examined the efficiency of Bitcoin's markets and found its efficiency. According to this study, there were no anomalies of Bitcoin's prices in a week. Jakub (2015) showed that Bitcoin follows the hypothesis of efficient markets. In a different recent study, Urquhart (2016) indicated that the Bitcoin market had been inefficient until recently. It also showed that simplicity, transparency, and popularity have been increasing. Urquhart (2017) found that Bitcoin's price and volume have a significant positive relationship. Li and VVang (2017) indicated that Bitcoin prices adjust to economic fundamentals and market conditions. Vassilladis, Papadopoulos, Ranquoussi, and Konieczny (2017) found that there is a correlation between Bitcoin prices and stock prices. Hong (2017) showed that Bitcoin returns are similar to those of the other asset returns over a shorter time span. Stock prices may have to be taken into account when examining the Bitcoin's price along with exchange rates and Bitcoin's trading volume.

This article is structured as follows: Section 2 provides a model for Bitcoin's price volatility. Section 3 examines the data employed here. Based on section 3, section 4 shows empirical methods and provides empirical analyses. Finally, section 5 gives a brief conclusion.

\section{Price Volatility}

This study examines Bitcoin's price volatility. Along with the price itself (level), the rerun is also used for estimation. Bitcoin returns $(\mathrm{R})$ are calculated as follows in equation 1 :

$$
R t=\ln (P t / P t-1)
$$

where $\mathrm{Rt}$ is the return of Bitcoin. $\ln (\mathrm{Pt})$ and $\ln (\mathrm{Pt}-1)$ are the natural $\operatorname{logs}$ of Bitcoin prices at time $\mathrm{t}$ and $\mathrm{t}-1$. Data used in this study are daily.

Also, Augmented Dickey-Fuller tests (ADF) and Phillips-Perron tests (PP) were used to examine whether or not the null hypothesis of a unit root of the Bitcoin's returns and Bitcoin's levels cannot be accepted. ADF are used mostly for empirical estimation to check the unit root, however, if the series is correlated at higher order lags, the assumption of white noise disturbances can be violated. In such cases, the PP test provides a method to control for higher order serial correlation in a series than is accepted. This test makes a nonparametric correction to the t-test statistic.

This paper is to examine the price volatility of Bitcoin. To examine the data volatility, the GARCH model is sometimes useful. The GARCH model was introduced by Engle (1982), Bollerslev (1986), and Taylor (1986). This model is often used especially in financial time-series analysis. An agent in financial markets predicts the period's variance by forming a weighted average of a long term average, the forecasted variance from last period 
(GARCH term), and information about volatility observed in the previous period (ARCH term). If the asset return was unexpectedly large in either the upward or the downward direction, the trader will increase the estimate of the variance for the next period. In this study, the basic GARCH is expressed in equation 2.

$$
\begin{gathered}
R t=\alpha 0+\sum_{i=1}^{s} \alpha i R t-i+\varepsilon t \\
\varepsilon t=\text { hizi } \quad \text { zi } \sim \text { i.i.d. }(0,1)
\end{gathered}
$$

where $\varepsilon t$ is the error term, zi is a white noise process, and hi is the conditional standard deviation.

\section{Data}

The Bitcoin data are from www.bitcoinaverage.com which is an aggregated Bitcoin index of prices from Bitcoin markets. First, the level (level in Table 1) and the data that are converted level into rate (rate in Table 1) are examined for each day. The sample period is from 7/17/2010 to 12/29/2016. The descriptive statistics of Bitcoin for the whole period are shown in Table 1.

Table 1. Descriptive data and unit root tests

\begin{tabular}{lcc}
\hline & Rate & Level \\
\hline Mean & -0.002 & 243.876 \\
Median & -0.0008 & 145.140 \\
Maximum & 0.559 & 1183.590 \\
Minimum & -0.310 & 0.050 \\
Std. Dev & 0.054 & 258.589 \\
Skewness & 1.494 & 0.778 \\
Kurtosis & 21.504 & 2.516 \\
Jarque-Bera & 34416.23 & $260.642^{* * *}$ \\
ADF & $-23.205^{* * *}$ & -2.249 \\
PP & $-39.858^{* * *}$ & $-2.657^{*}$ \\
\hline$* * * *$ & &
\end{tabular}

The returns are positively skewed while the excess kurtosis suggests leptokurtic behavior. The value of the Jarque-Bera statistics indicate the departure from normality. In addition, Augmented Dickey-Fuller (ADF) and Phillips-Perron unit-root tests show that they accept the null hypothesis of a unit root for the returns at $1 \%$ significant level, so stationarity is guaranteed. The stationarity is guaranteed for the cases of return, but stationarity cannot be found for the case of the level. Examining the volatility justifies the application of GARCH models. In section 4, the return of Bitcoin instead of the price level of Bitcoin is used for estimation.

\section{Empirical Analysis}

\subsection{GARCH Model}

Using the GARCH model, price volatility of Bitcoin is examined in this section. The basic estimated equation is (2) as shown in section 2. In addition to basic the GARCH model, EGARCH, PGARCH, and CGARCH models are employed for estimation.

In exponential GARCH (EGARCH), the leverage effect is exponential rather than quadratic, and the forecasts of the conditional variance are guaranteed to be nonnegative. Power GARCH (PGARCH) employs a power parameter. The power parameter, which is the standard deviation, is estimated rather than imposed. Component GARCH (CGARCH) uses the variables in the transitory estimation. They have an impact on the short-term movements in volatility while the variables in the permanent equation will impact the long-term levels of volatility. In this study, GARCH $(1,1)$ is used for estimation when employing the CGARCH model. The results are (a), (b), (c), and (d) in Table 2. 
Adding to the GARCH models, Ordinary Least Squares (OLS), Generalized Method of Moments (GMM), and robust least squares (RLS) estimation methods are also employed for estimation. RLS is unlike maximum likelihood estimation. Employing OLS estimation for regression is sensitive to the observations that do not follow the pattern of the other observations. This is not a problem if the outlier is simply an extreme observation from the tail of a normal distribution; however, if the outlier is from non-normal measurement error or some other violation of standard OLS, it compromises the validity of the regression results if a nonrobust regression method is employed. The results are (e), (f), and (g) in Table 2.

The results in Table 2 show that the GARCH model appears to be an appropriate test to describe the volatility of the Bitcoin price returns.

Table 2. Estimated results of bitcoin's returns

\begin{tabular}{|c|c|c|c|c|c|c|c|}
\hline & $\begin{array}{l}\text { GARCH } \\
\text { (a) }\end{array}$ & $\begin{array}{c}\text { EGARCH } \\
\text { (b) }\end{array}$ & $\begin{array}{c}\text { PGARCH } \\
\text { (c) }\end{array}$ & $\begin{array}{l}\text { CGARCH } \\
\text { (d) }\end{array}$ & $\begin{array}{l}\text { LS } \\
\text { (e) }\end{array}$ & $\begin{array}{l}\text { GMM } \\
\text { (f) }\end{array}$ & $\begin{array}{c}\text { Robust Least Squares } \\
\text { (g) }\end{array}$ \\
\hline \multirow[t]{2}{*}{ Const. } & $0.001^{* * *}$ & $0.004^{* * *}$ & $0.002^{* * *}$ & $0.001^{* * *}$ & $0.004^{* * *}$ & $-0.021^{* * *}$ & $0.002^{* * *}$ \\
\hline & $(0.0004)$ & $(0.0002)$ & $(0.0004)$ & $(0.0003)$ & $(0.001)$ & $(0.007)$ & $(0.009)$ \\
\hline \multirow[t]{4}{*}{$\mathrm{R}(-1)$} & $0.188^{* * *}$ & $0.176^{* * *}$ & $0.1988^{* * *}$ & $0.186^{* * *}$ & $0.203^{* * *}$ & $5.036^{* * *}$ & $0.256^{* * *}$ \\
\hline & $(0.021)$ & $(0.021)$ & $(0.020)$ & $(0.018)$ & $(0.020)$ & $(0.993)$ & $(0.009)$ \\
\hline & Variance & Variance & Variance & Variance & & & \\
\hline & Equation & Equation & Equation & Equation & & & \\
\hline Const. & $\begin{array}{l}4.63 \mathrm{E}-05^{* * *} \\
(1.47 \mathrm{E}-06)\end{array}$ & & & & & & \\
\hline $\operatorname{Redid}(-1)^{\wedge} 2$ & $\begin{array}{l}0.359^{* * *} \\
(0.015)\end{array}$ & & & & & & \\
\hline GARCH(-1) & $\begin{array}{l}0.708^{* * *} \\
(0.007)\end{array}$ & & & & & & \\
\hline $\mathrm{C}(3)$ & & $\begin{array}{l}-0.776^{* * *} \\
(0.029)\end{array}$ & $\begin{array}{c}0.0002^{* * *} \\
(5.10 \mathrm{E}-05)\end{array}$ & $\begin{array}{l}0.001^{* * *} \\
(0.0003)\end{array}$ & & & \\
\hline$C(4)$ & & $\begin{array}{l}0.488^{* * *} \\
(0.018)\end{array}$ & $\begin{array}{l}0.320^{* * *} \\
(0.015)\end{array}$ & $\begin{array}{l}0.999^{* * *} \\
(0.0001)\end{array}$ & & & \\
\hline $\mathrm{C}(5)$ & & $\begin{array}{l}0.079^{* * *} \\
(0.011)\end{array}$ & $\begin{array}{l}-0.118^{* * *} \\
(0.023)\end{array}$ & $\begin{array}{l}0.147^{* * *} \\
(0.004)\end{array}$ & & & \\
\hline$C(6)$ & & $\begin{array}{l}0.931^{* * *} \\
(0.003)\end{array}$ & $\begin{array}{l}0.739^{* * *} \\
(0.009)\end{array}$ & $\begin{array}{l}0.143^{* * *} \\
(0.010)\end{array}$ & & & \\
\hline$C(7)$ & & & $\begin{array}{l}1.611^{* * *} \\
(0.065)\end{array}$ & $\begin{array}{l}0.741^{* * *} \\
(0.021)\end{array}$ & & & \\
\hline Adj. $R^{2}$ & 0.036 & 0.039 & 0.038 & 0.036 & & -22.808 & \\
\hline Adj. $\mathrm{Rw}^{2}$ & & & & & & & 0.220 \\
\hline F-statistic & & & & & $\begin{array}{l}98.662 \\
(0.000)\end{array}$ & & \\
\hline $\mathrm{Rn}^{2}$ statistic & & & & & & & $\begin{array}{r}797.806 \\
(0.000)\end{array}$ \\
\hline D.W. & 1.921 & 1.905 & 1.944 & 1.916 & 1.955 & 1.989 & \\
\hline AIC & -3.887 & -3.873 & -3.891 & -3.904 & -3.022 & & 4063.293 \\
\hline HQ & -3.883 & -3.868 & -3.885 & -3.898 & -3.021 & & \\
\hline J-statistic & & & & & & $2.19 \mathrm{E}-47$ & \\
\hline
\end{tabular}


The results are interesting to note. There are not large differences among the GARCH models, however, CGARCH model is the most appropriate model among the GARCH models judging from the Akaike Information Criteria (AIC) and Hanna-Quinn Criteria (HQ), which are similar to results discussed in Katsimpa (2017) and Bouoiyour and Selmi (2015). When examining the Bitcoin's prices, traders should see the volatilities, the short-run changes in volatility, and the long- run changes of volatility.

\subsection{Departure Spam}

Three additional analyses were performed in this section. First, the time span the departure time from the price rate trend, is calculated. As the trend returns, the Hodrick-Prescott method is used. This method is used to obtain a smoothed-curve representation of a time series, one that is more sensitive to long-term than to short-term fluctuations. The adjustment of the sensitivity of the trend to short-term fluctuations is achieved by modifying a multiplier. The difference between Bitcoin's return minus its Hodrick-Prescott value (HP) is regressed by the value of two days prior. The estimated equation is showin in equation 3.

$$
R t-H P t=\alpha(R t-2-H P t-2)
$$

The result is as follows (4).

$$
R t-H P t=0.219^{* * *}(R t-2-H P t-2)
$$

$$
\text { (0.020) }
$$

Adj.R2: 0.047 F-statistic: 24.343 (probability: 0.000) D.W.: 2.052

Parentheses are standard errors of deviation. As the time span departs from the trend, $10 \%$ is used. So, $0.219^{\mathrm{X}}=$ $0.1(10 \%)$ is solved. The result is that 1.516 day. When examining the Bitcoin's return, only focusing on short-term ones is not sufficient. There is some possible departure from the trend that would diminish or disappear but continue for some time. Irrational movements or shock would also continue for some time.

Moreover, another analysis is conducted. Bitcoin's rerun is regressed by exchange rate and stock prices. Both explanatory variables are rates (rexchange and rstock). For the exchange rate, daily average change rate of Japanese yen/US dollar exchange rate (rexchange), and for the stock prices, daily NIKKEI 225 daily average change rate are used for estimation. The estimated result is as follows (5).

$$
\begin{aligned}
& R t=-0.002^{* *}-0.235 \text { rexchange }+0.033 \text { rstock } \\
& (0.01) \quad(1.191)
\end{aligned}
$$

Adj.R2: -0.0001 F-statistic: 0.796 (probability: 0.451) D.W.: 1.622

Finally, Bitcoin's return is regressed by its daily change rate of trading volume (rvolume). The empirical result is the equation 6.

$$
\begin{aligned}
& R t=-0.002^{* *}+7.65 \text { E-05rvolume } \\
& (0.01) \quad(0.0007)
\end{aligned}
$$

Adj.R2: -0.0004 F-statistic: 0.011 (probability: 0.914) D.W.: 1.622

As the equations indicate, Bitcoin's price has not influenced other economic variables such as exchange rate or stock prices. Also, trading volume has not impacted Bitcoin prices. On the other hand, as suggested by the equations (e), (f), and (g) in Table 2, Bitcoin's price itself has an impact on the price, so its variance should be examined carefully as this study suggests.

\section{Conclusions}

This paper focused on the price volatility of Bitcoin by using empirical methods. The empirical results show that there is a difference between short-term volatility and long-term volatility. Traders should pay attention to both short-term and long-term movements in volatility.

Sound trading and boosting economies via Bitcoin is expected. Examination of Bitcoin's market has begun just recently. Experiences and data will be accumulated, and much more research from many aspects is expected.

\section{References}

Abboushi, S. (2017). Global virtual currency. The Journal of Applied Business and Economics, 19(6), 10-18.

Baek, C., \& Elbeck, M. (2015). Bitcoin as an investment or speculative vehicle? A first look. Applied Economics Letters, 22(1), 30-34. https://doi.org/10.1080/13504851.2014.916379 
Beer, C., \& Weber, B. (2014). Bitcoin: The promise and limits of private innovation in monetary and payment systems. Monetary Policy and the Economy, Q4/14.

Bollerslev, T. (1986). Generalized autoregressive conditional heteroscedasticity. Journal of Econometrics, 31(3), 307-327. https://doi.org/10.1016/0304-4076(86)90063-1

Bouoiyour, J., \& Selmi, R. (2015). Bitcoin Price: Is it really that new round of volatility can be on way? MPRA Paper No. 65580. Retrieved from https://mpra.ub.uni-muenchen.de/65580/1/MPRA_paper_65580.pdf

Brandvold, M., Molnar, P., Vagstad, K., Andreas, V., \& Ole, C. (2015). Price discovery on Bitcoin exchange. Journal of International Financial Markets, Institutions and Money, 36, 18-35. https://doi.org/10.1016/j.intfin.2015.02.010

Brère, M., Oosterinck, K., \& Szafarz, A. (2015). Virtual currency, tangible return: Portfolio diversification with Bitcoin. Journal of Asset Management, 16(6), 365-373. https://doi.org/10.2139/ssrn.2324780

Cheah, E. T., \& Fry, J. (2015). Speculative bubbles in Bitcoin markets? An empirical investigation into the fundamental value of Bitcoin. Economic Letters, 130, 32-36. https://doi.org/10.1016/j.econlet.2015.02.029

Cheung, A., Roca, E., \& Su, J.-J. (2015). Crypto-currency bubbles: An application of the Phillips-Shi-Yu (2013) methodology on Mt. Gox Bitcoin prices. Applied Economics, 47, 2348-2358. https://doi.org/10.1080/00036846.2015.1005827

Dowd, K., \& Hutchinson, M. (2015). Bitcoin will bite the dust. Cato Journal, 35(2), 357-382.

Dwyer, G. P. (2014). The economics of Bitcoin and similar private digital currencies. Journal of Financial Stability, 17, 81-91. https://doi.org/10.1016/j.jfs.2014.11.006

Dyhrberg, A. H. (2016). Hedging capabilities of Bitcoin: Is it the virtual gold? Finance Research Letters, 16, 139-144. https://doi.org/10.1016/j.frl.2015.10.025

Engle, R. (1982). Autoregressive conditional heteroscedasticity with estimates of the variance of United Kingdom Inflation. Econometrica, 50(4), 987-1007. https://doi.org/10.2307/1912773

Gronwald, M. (2014). The economics of Bitcoins: Market characteristics and price jumps. CESifo Working Paper Series No. 5121.

Hong, K. (2017). Bitcoin as an alternative investment vehicle. Information Technology and Management, 18(4), 265-275. https://doi.org/10.1007/s10799-016-0264-6

Jakub, B. (2015). Does Bitcoin follow the hypothesis of efficient market? International Journal of Economic Sciences, 4(2), 10-23. https://doi.org/10.20472/ES.2015.4.2.002

Katsimpa. P. (2017). Volatility estimation for Bitcoin: A comparison of GARCH models. Economics Letters, 158, 3-6. https://doi.org/10.1016/j.econlet.2017.06.023

Kurihara, Y., \& Fukushima, A. (2017). The market efficiency of Bitcoin: A weekly anomaly perspective. Journal of Applied Finance \& Banking, 7(3), 57-64.

Li, X., \& VVang, C. A. (2017). Decision support systems, 95, 49-60.

Maftei, L. (2014). Bitcoin: Between legal and informal. CES Working Papers, 6(3), 53-59.

McCallum, B. T. (2015). The Bitcoin revolution. Cato Journal, 35(2), 347-356.

Nakamoto, S. (2009). Bitcoin: A peer-to-peer electronic cash system. Retrieved January 3, 2017, from https://bitcoin.org/bitcoin.pdf\#search=\%27Nakamoto+2009+Bitcoin\%27

Seigh, G. (2015). Synthetic commodity money. Journal of Financial Stability, 17, 92-99. https://doi.org/10.1016/j.jfs.2014.07.002

Taylor, S. J. (1986). Modelling Financial Time Series. Chichester: Wiley.

Urquhart, A. (2016). The inefficiency of Bitcoin. Economics Letters, 148, 80-82. https://doi.org/10.1016/j.econlet.2016.09.019

Urquhart, A. (2017). Price clustering in Bitcoin. Economics letters, 159, 145-148. https://doi.org/10.1016/j.econlet.2017.07.035

Vassilladis, S., Papadopoulos, P., Ranquoussi, M., \& Konieczny, T. (2017). Bitcoin value analysis based on cross-correlations. Journal of Internet Banking and Commerce, 22 (S7), 1-12.

William, L. J. (2016). Bitcoin and future of digital payments. Independent Review, 20(3), 397-404. 
Yamori, N., \& Kurihara, Y. (2004). The day-of-the-week effect in foreign exchange markets: Multi-currency evidence. Research in International Business and Finance, 18(1), 51-57. https://doi.org/10.1016/j.ribaf.2004.02.004

Yermack, D. (2013). Is Bitcoin a real currency? NBER Working Papers No. 19747.

Zhu, Y., Dickinson, D., \& Li, J. (2017). Analysis on the influence factors of Bitcoin's price based on VEC model. Financial Innovation, 3(1), 1-13. http://dx.doi.org/10.1186/s40854-017-0057-x

\section{Copyrights}

Copyright for this article is retained by the author(s), with first publication rights granted to the journal.

This is an open-access article distributed under the terms and conditions of the Creative Commons Attribution license (http://creativecommons.org/licenses/by/4.0/). 